\title{
Is Academic Medicine Making Mid-Career Women Physicians Invisible?
}

\author{
Resa E. Lewiss, MD, ${ }^{1}$ Julie K. Silver, MD, ${ }^{2}$ Carol A. Bernstein, MD, ${ }^{3}$ Angela M. Mills, MD, ${ }^{4}$ \\ Barbara Overholser, $M A^{5}$, and Nancy D. Spector, MD $^{6}$
}

\begin{abstract}
In this perspective piece, we describe a multifactorial phenomenon whereby academic women physicians become invisible in the mid-career stage. Barriers, both small and large, cause a cumulative inequity effect, and women may leave academic medicine. Certainly, family and lifestyle choices play a role. And as we describe, so is a situation created where women become discouraged and disillusioned. We describe the growing evidence of subtle disparities, or micro-inequities, that cause women to be less visible and marginalized. Over time, early career women transition to mid-career with an accumulation of these micro-inequities. Women have more difficulty in building their academic portfolios and curriculum vitae-core components of academic promotion. They comprise greater than $50 \%$ of the health care workforce; yet, they are underrepresented in top leadership positions. For example, only $22 \%$ of full professors, $18 \%$ of department chairs, and $17 \%$ of medical school deans are women. Macro-inequities, which are observable and measurable, are also well documented. For example, women receive less compensation than men for the same job. We examine the contributing and causative processes and offer suggestions on how to promote equity among highly qualified mid-career women as they graduate from training and move beyond the early career stage.
\end{abstract}

Keywords: gender equity, mid-career physician, promotion, leadership, invisibility

\section{Introduction}

$\mathbf{R}$ ESEARCH SHOWS THAT diversity can have a measurable impact on the return on investment, project completion, and retention of talent for organizations. Since diversity affords strength, innovation, and increased productivity to organizations, the evidence suggests that gender diverse teams may be more successful. It is thus beneficial for organizations to have women present and leading. ${ }^{1,2}$

Diversity can mean many different things, including the impact that race, ethnicity, background, and other factors play in creating work environments. For this article, we focus on gender equity and women in the mid-career. Nonetheless, we acknowledge the compounding effect and importance that intersectionality plays for mid-career women.

Highly qualified women can be disregarded, ignored, and fall out of academic consideration as they mature from the training and early career to mid-career stages. The phenom- enon of invisibility that occurs at the academic mid-career has been described, and we build upon this premise. Our primary goal is to describe what happens, and secondarily, we offer potential solutions.

\section{The invisibility of some mid-career women}

Women comprise greater than $50 \%$ of the health care workforce; yet, they are underrepresented in top leadership positions. For example, only $22 \%$ of full professors, $18 \%$ of department chairs, and $17 \%$ of medical school deans are women ${ }^{3}$ Moreover, women are less likely than men to hold the rank of Associate or Full Professor, even after adjusting for factors that may be associated with academic advancement, such as age, years since residency, publications, grants, clinical trials, medical school ranking, and total Medicare payments. ${ }^{4,5}$ A recent study found that no women held presidential leadership positions among 10 major medical specialty

\footnotetext{
${ }^{1}$ Department of Emergency Medicine, Thomas Jefferson University, Philadelphia, Pennsylvania.

${ }^{2}$ Department of Physical Medicine and Rehabilitation, Harvard Medical School, Charlestown, Massachusetts.

${ }^{3}$ Department of Psychiatry and Behavioral Sciences, Montefiore Medical Center/Albert Einstein College of Medicine, Bronx, New York.

${ }^{4}$ Department of Emergency Medicine, Columbia University Vagelos College of Physicians and Surgeons, New York, New York.

${ }^{5}$ Executive Leadership in Academic Medicine Program, Drexel University College of Medicine, Philadelphia, Pennsylvania.

${ }^{6}$ Drexel University College of Medicine, Philadelphia, Pennsylvania.
} 
societies in the last decade. ${ }^{6}$ Even among specialties with a high number of women entering the field (e.g., Pediatrics and Obstetrics-Gynecology), women are proportionally underrepresented as chairs and vice chairs. ${ }^{7,8}$

In 2007, Carnes and Bigby published a provocative editorial "Jennifer fever in academic medicine." 9 The authors described a phenomenon that more than a decade later is relevant to the mid-career invisibility of many women. Trainee and early career stage women, or "Jennifers," receive professional attention and a professional development focus by their more senior male colleagues and superiors. However, attitudes shift and as they advance to mid-career: the intentional attention and support wane and these women become invisible. The authors describe a pattern of mythologizing and "justified distancing" of women in the midcareer as they become more of a threat. Seven years later, Kaatz and Carnes published an editorial building on the "Jennifer fever" concept and illustrated an invisibility pattern as women progress through career stages. ${ }^{10}$ The authors explain that superiors pay attention to women at the early stage of career, when they are young, less accomplished, and less threatening. However, as they gain experience and accomplishments, women are often dismissed and marginalized based on gender stereotypes. A multifactorial phenomenon occurs for some women at mid-career.

\section{Bias}

Bias impacts some women from the first day of medical school and follows them steadily into mid-career-a time when they should be advancing in academic medicine. Early career women may leave academic medicine for a myriad of reasons, and compared with men, they leave at lower academic ranks. ${ }^{11}$ Narratives of physician self-reported reasons highlight a lack of later career stage role models, difficulty in obtaining research funding, work-life balance challenges, and an institutional culture, which favors men. ${ }^{12}$

Academic productivity may be influenced by family and/ or work-life choices, which some women make in their early careers. Yet, the literature shows that this does not adequately account for gaps in mid-career representation. Instead, there are systemic forms of bias, which prevent women from achieving what would be anticipated based on their education, training, and academic accomplishments. Implicit bias, for example, is unconscious and is a set of commonly held beliefs about a certain group. An illustration of implicit bias is determining that women are nurturing and communal and therefore not good leaders. Organizational bias is more difficult to identify as it is woven into the organization's culture. Therefore, the organizational leaders and strategic team have integrated this bias such that decisions are not based on merit. An illustration of organizational bias is a perpetual pattern of appointing men to department chair positions despite a pool of equally qualified women. Relatedly, stereotype threat is a phenomenon whereby members of a certain group characterized by negative stereotypes perform below their actual abilities. The negative emotional impact of negative stereotypes may cause stress, anxiety, or disappointment, thus leading to underperformance and underachievement, or stereotype threat. For example, women in a sexist environment perform more poorly than in an environment not felt to be sexist and threatening. ${ }^{13}$
The consequences of implicit and organizational biases accumulate over time. Thus, disparities in early career build, and by mid-career, women in academic medicine are often systematically disadvantaged. Too often the women, not the organizational systems that work against them, are blamed for this.

\section{Inequities}

In 1970, Chester Pierce, MD, coined the term microaggression to describe race- and ethnicity-based subtle snubs, slights, and insults. Often nonverbal, microaggressions target a marginalized group, and the cumulative effect of such experiences can cause harm. An example of a microaggression would be a woman physician introducing herself as Dr. XX yet being called by her first name " $X$ " rather than by her professional title Dr. XX. In 1973, Mary Rowe, PhD, coined the term micro-inequities, which are less likely hostile or aggressive, but rather stem from unconscious bias. ${ }^{14}$ In workplace cultures where microinequities are frequent, people become accustomed to them and do not see a need to address them. Micro-inequities and microaggressions are additive, burdensome, and they contribute to some women leaving at the mid-career stage. While micro-inequities are subtler and more difficult to measure, the macro-level gender inequities are not. Women lag behind men in countless areas: leadership positions, first authorship on publications, research funding, evaluations, awards, promotions, and salary. ${ }^{15-20}$

Barriers to promotion and advancement may include inequities in speaking opportunities, lectureships, and award recognition, as these are line items on an academic curriculum vitae.

Mid-career is arguably when women most need robust letters of recommendation. They need speaking opportunities, with introductions that position them as subject matter experts. They need amplification of their work in medical society newsletters that go to thousands of colleagues, who may then think of them for future research collaborations, speaking opportunities, or nominate them for awards. Women are underrepresented as speakers at national conferences and academic grand rounds. ${ }^{21,22}$ They are less likely than men to receive achievement awards and are less likely to be nominated. ${ }^{18,19}$ Recommendation letters are shorter in length for women than for men and use less powerful language to describe women's professional accomplishments compared with those for men ${ }^{23}$; women receive fewer formal introductions on the speaker podium ${ }^{24}$ and are left out of medical society newsletters. $^{25}$

When women are not the lead authors on publications, are not introduced professionally or respectfully, and are equitably included on editorial boards, they slowly become invisible.

Salary and promotion disparities are considered macroinequities; however, they are likely supported by many years of cumulative microinequities. Fair compensation is among the most important of the macro-inequities, and women physicians earn less than their male counterparts with persistent differentials noted even after adjusting for potential confounders, such as age, race, ethnicity, medical specialty, years in practice, patient care hours, and procedures performed. ${ }^{16,26}$ Even when compensation appears to be comparable for people at the same level, women are often 
disadvantaged because they are not promoted equitably. For example, a woman who is an assistant professor for 10 years will receive less compensation than a man who is an assistant professor for 5 years and then is promoted to associate professor, and receives a greater compensation for 5 years.

There are gender disparities on many medical journal editorial boards, particularly at the highest levels. In general, women are underrepresented on medical journal editorial boards. And in a survey of 60 major medical journals, $16 \%$ of editors in chief and $18 \%$ of board members overall are women. ${ }^{27}$ The underrepresentation of highly qualified women on editorial boards, including the position of editor-inchief, is itself a macro-inequity, and it may affect the ability of women to publish articles, obtain grants, and achieve promotions. $^{27-30}$

A final example of a gender-specific macro-inequity is the allocation of taxpayer dollars by government agencies, such as the National Institutes of Health (NIH). Women receive merely $25 \%$ of the NIH grants and $21 \%$ of total funding. The NIH grants awarded to women are $\sim 80 \%$ of the grant funding amount awarded to men. ${ }^{31,32}$ Such inequities lead to a lack of visibility of women in the most prestigious areas of academic medicine.

\section{Pregnancy and motherhood}

Pregnancy- and motherhood-related discrimination could occur at any career stage; yet, the immediate or downstream consequences are mostly likely apparent for a woman in her mid-career. If the structure and time clock for achieving progress in academia is not flexible enough to accommodate the competing domestic demands of families, then it is a woman's career trajectory, which most likely is negatively affected. ${ }^{15}$ Time spent on domestic labor competes with time spent conducting research, and research is arguably an activity critical to academic promotion and success. ${ }^{33}$ Disproportionately, having children negatively affects women's academic careers. ${ }^{34}$ And, the evidence suggests that this type of gender-based discrimination remains common in medicine. $^{35}$

Women, who are mothers, report being subjected to higher standards as physicians as a test of commitment and competence. They report being passed over for leadership positions. They are left out of administrative decisions due to pregnancy or maternity leave, and they receive lower salaries than colleagues with similar levels of experience and productivity. Colleagues make disrespectful and disparaging comments. For example, they describe maternity leave as a "vacation." Women physicians describe rules and expectations not expected of male colleagues, such as limited work leave options, and the need to find childcare to accommodate work hours. They describe a lack of alternative work schedules to support domestic responsibilities, and the pressure to complete administrative tasks after hours. ${ }^{33}$ Maternal discrimination and its ultimate effects on women in the midcareer stage contribute to invisibility in a few ways. Women, who are mothers, may decide to leave their positions or to step out of academic medicine because they feel that they are not supported or respected. At the same time, organizations and their bosses make them invisible by not creating an inclusive and accommodating culture.

\section{Sexual harassment}

Sexual harassment plays an important, increasingly appreciated, and measurable role in the actions and decisions of academic women physicians. Sexual harassment is an umbrella term, which includes acts, words, and behaviors of coercion, unwanted attention, and gender harassment. Sexual harassment is common in medicine. ${ }^{36}$ According to the 2018 NASEM report, women in medicine report the highest prevalence of sexual harassment of all Science, Technology, Engineering, Mathematics, and Medicine (STEMM) specialties. The report describes a culture, whereby sexual harassment and gender bias in health care have been normalized, and the true incidence and prevalence are probably higher than reported for a variety of reasons (e.g., underreporting by those affected). ${ }^{36}$ Over time, sexual harassment and microaggressions build up and cause negative professional and psychological outcomes. Sexual harassment undermines professional attainment, mental health, and physical health of women. Ultimately, some women leave and cumulatively, talent is lost at the mid-career. Women disappear into invisibility.

\section{Reducing invisibility and increasing recognition for mid-career women}

Maintaining and increasing the visibility of mid-career women and recognizing them for their contributions are paramount to their success in academic medicine. This requires a conscious effort on the part of individuals, health care institutions, medical societies, and other organizations.

The Athena SWAN Charter, established in 2005, is one example of a top-down designed change intervention. In other words, United Kingdom-based institutional leaders are held responsible to improve the status of women in their respective organizations, and the responsibility is not placed upon the women. ${ }^{37}$ Traditionally, academic medicine has taken the bottom-up approach to gender equity, with much of the expectation of proof being placed upon women. The Charter intends to recognize and encourage a commitment to advancing the careers of women in STEMM by institutions of higher education and research. Since 2011, support from some United Kingdom funding bodies is tied to the level of Athena SWAN award held. ${ }^{37}$

In their systemic review, Laver et al. similarly advocate for gender equity solutions that come from the top. ${ }^{38}$ These are more effective, than those, which place responsibility on women to do the work themselves. The authors acknowledge the limited evidence on the best practices to improve retention rates, promotion, research grant acquisition, and salary equity for women. ${ }^{38}$

We briefly describe some interventions that address and reverse the invisibility of mid-career women physicians.

\section{Gender bias training}

Since gender-stereotyped assumptions often underlie and influence the decisions of individuals and institutions, leaders must first determine and recognize when such bias is at play. Gender bias workshops and trainings increase knowledge and raise awareness; yet, few reports assess a work climate change. ${ }^{39}$ There is some evidence to suggest that gender bias training, which focuses on intentional behavior change 
among faculty, can change the gender equity climate. ${ }^{40}$ Such training may even trend toward of hiring more women faculty. 40

\section{Mentorship, sponsorship, and leadership trainings}

Mentorship and sponsorship relationships are commonly identified solutions. Mentorship is coaching and developing a relationship with an individual with the goal of professional growth. For these relationships, the mentor is presumed to have more experience and expertise than the mentee. Some studies report the positive effects of peer mentoring, specifically for skills and self-esteem building. ${ }^{38}$ In contrast, sponsorship is the utilization of power and influence to advocate for an individual. There may not be a personal or ongoing relationship between the sponsor and the person being sponsored. However, the literature suggests that mentorship does not necessarily translate to promotions for women. $^{41,42}$ so sponsors are arguably the more important relationship. Sponsors have the position and power to advocate for advancement. Thus men, who occupy the majority of dean, chair, journal editor-in-chief, professor, and other leadership positions, have the ability to sponsor mid-career academic women, affect career advancement and elevate women to executive leadership positions. ${ }^{42-44}$

Leadership training programs, such as mid-career leadership seminars, ${ }^{45}$ and the Executive Leadership in Academic Medicine $^{46}$ have reported that positive benefits such as skills building, increased representation, promotions, retention, and remuneration play a role in promoting gender equity. ${ }^{38}$ Sponsors and institutional leaders should support women attending faculty development opportunities and leadership trainings in the mid-career to maintain visibility.

\section{Speaking, publishing, and editorial boards}

Recently, the NIH director Francis Collins declared that he would no longer participate in all male panels or "manels." This may accelerate a culture shift at scientific and medical society conferences, where women are often excluded or represented in small numbers. ${ }^{47}$ In doing so, Collins acknowledged the invisibility of women and underrepresented groups in lead speaking slots and high-level professional meetings. Moreover, this admission highlighted an important issue - the NIH has had a longstanding policy focused on the inclusion of women on panels and other speaking opportunities. And some people are not minding the policy. Without metrics tracking the inclusion of women and enforcement of the policy, it has been ineffective. There are speaker bureaus and web-based organizations from which women speakers or women co-authors can be invited. ${ }^{48,49}$ This visibility can be prioritized for not only the spoken but also the written word. For example editors in chief and journal editorial boards should seek to equally represent women on their boards. ${ }^{26,28}$

\section{Grants and re-entry fellowships}

The NIH created the Office of Research on Women's Health that focuses in part on gender-related grant and publication issues. ${ }^{50}$ Training grants must document the recruitment of women at the early career level. Yet, there is no responsibility include and to demonstrate advancing mid- career women, and consequently, they are not intentionally visible. Jagsi et al. reported the success of a focused institutional intervention: an internal financial grant for women with childcare responsibilities. Positive outcomes among grant recipients included an increased rate of promotion, an optimistic career attitude, and success in receiving subsequent grant funding. ${ }^{51}$

\section{Conclusion}

Mid-career women in academic medicine are at continued risk of being made invisible. There is a large body of evidence suggesting that medicine has not proven to be a meritocracy, where everyone's accomplishments are viewed and rewarded equally. There is a tremendous need for more research on workforce gender equity, especially on interventions. Mid-career is a critical time for all physicians, and disparities for women need to be addressed in a scientific and expedient manner. It is especially important for the academic community to recognize that women, in particular, continue to lose ground at this juncture and are unable to be equitably represented at all levels of medicine including top leadership positions. The phenomenon of mid-career invisibility maintains the status quo of gender inequity in academic medicine. By understanding the transition from training to early and to mid-career, leaders can focus on recognizing women's accomplishments and contributions to academic medicine.

\section{Author Disclosure Statement}

Dr. Nancy Spector holds equity in and has consulted with the I-PASS Patient Safety Institute. The I-PASS Patient Safety Institute is a company that seeks to train institutions in best handoff practices and aid in their implementation. Dr. Spector has additionally received monetary awards, honoraria, and travel reimbursement from multiple academic and professional organizations for teaching and consulting on physician performance and handoffs. None of the remaining authors have any financial interests to disclose.

\section{Funding Information}

No funding was received for this article.

\section{References}

1. Why Diverse Teams Are Smarter. Available at: https://hbr .org/2016/11/why-diverse-teams-are-smarter Accessed January 11, 2019.

2. Why Diversity Matters. Available at: https://www.mckinsey .com/business-functions/organization/our-insights/whydiversity-matters Accessed January 11, 2019.

3. Association of American Medical Colleges. Faculty Roster website. Available at: https://www.aamc.org/data/faculty roster/reports Accessed January 12, 2019.

4. Carr PL, Raj A, Kaplan SE, Terrin N, Breeze JL, Freund KM. Gender differences in academic medicine: Retention, rank, and leadership comparisons from the National Faculty Survey. Acad Med 2018;93:1694-1699.

5. Bennett CL, Raja AS, Kapoor N, et al. Gender differences in faculty rank among academic emergency physicians in the United States. Acad Emerg Med 2019.

6. Silver JK, Ghalib R, Poorman JA, et al. Analysis of gender equity in leadership of physician-focused medical specialty 
societies, 2008-2017. JAMA Intern Med 2019;179:433435.

7. Hofler LG, Hacker MR, Dodge LE, Schutzberg R, Ricciotti HA. Comparison of women in department leadership in obstetrics and gynecology with those in other specialties. Obstet Gynecol 2016;127:442-447.

8. Davis T, Goldstein H, Hall D, et al. Women and children first? Gender equity in paediatric medicine. Arch Dis Child 2019. [Epub ahead of print]; DOI: 10.1136/archdischild2018-316586.

9. Carnes M, Bigby J. Jennifer fever in academic medicine. J Womens Health (Larchmt) 2007;16:299-301.

10. Kaatz A, Carnes M. Stuck in the out-group: Jennifer can't grow up, Jane's invisible, and Janet's over the hill. J Womens Health (Larchmt) 2014;23:481-484.

11. Cropsey KL, Masho SW, Shiang R, et al. Why do faculty leave? Reasons for attrition of women and minority faculty from a medical school: Four-year results. J Womens Health (Larchmt) 2008;17:1111-1118.

12. Levine RB, Lin F, Kern DE, Wright SM, Carrese J. Stories from early-career women physicians who have left academic medicine: A qualitative study at a single institution. Acad Med 2011;86:752-758.

13. Burgess DJ, Joseph A, van Ryn M, Carnes M. Does stereotype threat affect women in academic medicine? Acad Med 2012;87:506-512.

14. Silver JK, Rowe M, Sinha MS, Molinares DM, Spector ND, Mukherjee D. Micro-inequities in medicine. PM R 2018; 10:1106-1114.

15. Rochon PA, Davidoff F, Levinson W. Women in academic medicine leadership: has anything changed in 25 years? Acad Med 2016;91:1053-1056.

16. Apaydin EA, Chen PGC, Friedberg MW. Differences in physician income by gender in a multiregion survey. J Gen Intern Med 2018;33:1574-1581.

17. Jena AB, Khullar D, Ho O, Olenski AR, Blumenthal DM. Sex differences in academic rank in US medical schools in 2014. JAMA 2015;314:1149-1158.

18. Abbuhl S, Bristol MN, Ashfaq H, et al. Examining faculty awards for gender equity and evolving values. J Gen Intern Med 2010;25:57-60.

19. Silver JK, Bhatnagar S, Blauwet CA, et al. Female physicians are underrepresented in recognition awards from the American academy of physical medicine and rehabilitation. PM R 2017;9:976-984.

20. Aakhus E, Mitra N, Lautenbach E, Joffe S. Gender and byline placement of co-first authors in clinical and basic science journals with high impact factors. JAMA 2018;319: 610-611.

21. Boiko JR, Anderson AJM, Gordon RA. Representation of women among academic grand rounds speakers. JAMA Intern Med 2017;177:722-724.

22. Carley S, Carden R, Riley R, et al. Are there too few women presenting at emergency medicine conferences? Emerg Med J 2016;33:681-683.

23. Trix F and Psenka C. Exploring the color of glass: Letters of recommendation for female and male medical faculty. Discourse Soc 2003;2:191-220.

24. Files JA, Mayer AP, Ko MG, et al. Speaker introductions at internal medicine grand rounds: Forms of address reveal gender bias. J Womens Health (Larchmt) 2017;26:413419.

25. Silver JK, Reilly JM, Gallegos-Kearin V, Poorman JA, Bhatnagar S, Zafonte R. Poster 130: Women Physicians are often not visible in newsletters published by the American Academy of Physical Medicine and Rehabilitation. PM R 2018;10:S8-S8.

26. Ly DP, Seabury SA, Jena AB. Differences in incomes of physicians in the United States by race and sex: Observational study. BMJ 2016;353:i2923.

27. Amrein K, Langmann A, Fahrleitner-Pammer A, Pieber TR, Zollner-Schwetz I. Women underrepresented on editorial boards of 60 major medical journals. Gend Med 2011;8:378-387.

28. Jagsi R, Guancial EA, Worobey CC, et al. The "gender gap" in authorship of academic medical literature-A 35-year perspective. N Engl J Med 2006;355:281-287.

29. Silver JK, Poorman JA, Reilly JM, Spector ND, Goldstein $\mathrm{R}$, Zafonte RD. Assessment of women physicians among authors of perspective-type articles published in highimpact pediatric journals. JAMA Netw Open 2018;1: e180802.

30. Harris CA, Banerjee T, Cramer M, et al. Editorial (Spring) Board? Gender composition in high-impact general surgery journals over 20 years. Ann Surg 2019;269:582-588.

31. Newgard CD, Morris CD, Smith L, et al. The first National Institutes of Health Institutional Training program in emergency care research: Productivity and outcomes. Ann Emerg Med 2018;72:679-690.

32. Jagsi R, Motomura AR, Griffith KA, Rangarajan S, Ubel PA. Sex differences in attainment of independent funding by career development awardees. Ann Intern Med 2009; 151:804-811.

33. Halley MC, Rustagi AS, Torres JS, et al. Physician mothers' experience of workplace discrimination: A qualitative analysis. BMJ 2018;363:k4926.

34. Adesoye T, Mangurian C, Choo EK, et al. Perceived discrimination experienced by physician mothers and desired workplace changes: A cross-sectional survey. JAMA Intern Med 2017; 177:1033-1036.

35. Mason MA, Wolfinger NH, Goulden M. Do Babies Matter? New Brunswick, NJ: Rutgers University Press, 2013:28-29.

36. Johnson PA, Widnall SE, Benya FF, eds. Sexual Harassment of Women: Climate, Culture, and Consequences in Academic Sciences, Engineering, and Medicine 2018. Available at: https://www.nap.edu/catalog/24994/sexualharassment-of-women-climate-culture-and-consequencesin-academic Accessed July 8, 2019.

37. Donald A, Harvey PH, McLean AR. Athena SWAN awards: Bridging the gender gap in UK science. Nature 2011;478:36.

38. Laver KE, Prichard IJ, Cations M, Osenk I, Govin K, Coveney JD. A systematic review of interventions to support the careers of women in academic medicine and other disciplines. BMJ Open 2018;8:e020380.

39. Carnes M, Devine PG, Baier Manwell L, et al. The effect of an intervention to break the gender bias habit for faculty at one institution: A cluster randomized, controlled trial. Acad Med 2015;90:221-230.

40. Devine PG, Forscher PS, Cox WTL, Kaatz A, Sheridan J, Carnes M. A gender bias habit-breaking intervention led to increased hiring of female faculty in STEMM departments. J Exp Soc Psychol 2017;73:211-215.

41. Ibarra H, Carter NM, Silva C. Why men still get more promotions than women. Harv Bus Rev 2010;88:80-85, 126.

42. Ayyala MS, Skarupski K, Bodurtha JN, et al. Mentorship is not enough: Exploring sponsorship and its role in career 
advancement in academic medicine. Acad Med 2019;94: 94-100.

43. Travis EL, Doty L, Helitzer DL. Sponsorship: A path to the academic medicine C-suite for women faculty? Acad Med 2013;88:1414-1417.

44. Gottlieb AS, Travis EL. Rationale and models for career advancement sponsorship in academic medicine: The Time is here; the time is now. Acad Med 2018;93:1620 1623.

45. Mid-Career Faculty Leadership Development Seminar. Available at: https://www.aamc.org/members/leadership/ catalog/323118/mid-careerwomenfacultyleadershipdevelop mentseminar.html Accessed February 01, 2019.

46. Executive Leadership in Academic Medicine Program. Available at: https://drexel.edu/medicine/academics/womenshealth-and-leadership/elam Accessed February 1, 2019.

47. Time to End the Manel Tradition. Available at: https://www .nih.gov/about-nih/who-we-are/nih-director/statements/timeend-manel-tradition Accessed July 6, 2019.
48. 500 Women Scientists. Available at: https://500women scientists.org/who-we-are Accessed January 11, 2019.

49. FemInEM Speakers Bureau. Available at: https://feminem .org/speakers Accessed January 11, 2019.

50. National Institutes of Health Office of Research on Women's Health. Available at: https://orwh.od.nih.gov/careerdevelopment Accessed January 26, 2019.

51. Jagsi R, Butterton JR, Starr R, Tarbell NJ. A targeted intervention for the career development of women in academic medicine. Arch Intern Med 2007;167:343-345.

Address correspondence to:

Resa E. Lewiss, MD

Thomas Jefferson University 1025 College Building

Suite 300

Philadelphia, PA 19107-5084

E-mail: resaelewiss@gmail.com 